\title{
Clean-energy utilization technology in the transformation of existing urban residences in China
}

\author{
Li Zhao' ${ }^{1}$ Wei Chen ${ }^{2} \cdot$ Qiong $\mathrm{Li}^{2}$ (D) Weiwei $\mathrm{Wu}^{1}$
}

Received: 28 July 2020/Revised: 31 October 2020/Accepted: 6 March 2021 / Published online: 20 May 2021

(C) The Author(s) 2021

\begin{abstract}
Clean-energy substitution technology for existing residential buildings in cities is an inevitable choice for sustainable development and low-carbon ecological city construction. In this paper, the current status of energy-saving renovation and renewable-energy applications for existing residential buildings in various cities in China was summarized by using statistical methods. The geographical distribution of clean-energy power generation in primary energy production in China was explored in depth. According to different climatic divisions for existing urban residences, clean-energy production and consumption were analyzed and predicted based on the STIRPAT model. The results show that the energy consumption of urban residential buildings in 2016 increased by $43.6 \%$ compared with 2009, and the percentage of clean energy also increased from $7.9 \%$ to $13.4 \%$. Different climatic regions have different advantages regarding clean energy: nuclear power generation leads in the region that experiences hot summers and warm winters, whereas wind and solar power generation lead in the cold and severely cold regions. The present results provide basic data support for the planning and implementation of clean-energy upgrading and transformation systems in existing urban residences in China.
\end{abstract}

Keywords Existing urban residence $\cdot$ Clean-energy substitution $\cdot$ Climatic region $\cdot$ Ridge regression analysis $\cdot$ STIRPAT model

\section{Introduction}

Given climate change and economic development, promoting low-carbon communities in cities has become an important choice for all countries to achieve sustainable development (Dutta 2020). At the general debate of the 75th session of the United Nations General Assembly, China claimed that it aims to see its carbon dioxide $\left(\mathrm{CO}_{2}\right)$ emissions peak before 2030 and achieve carbon neutrality before 2060. The energy development target announced by the State Council of the People's Republic of China

Qiong Li

hdliqiong@163.com

1 China Academy of Building Research, Beijing 100013, China

2 College of Architecture and Civil Engineering, North China Institute of Science and Technology, Langfang 065201, China
(NDRC 2017a) stated that non-fossil energy should account for $15 \%$ of total primary energy consumption by 2020, and the Revolutionary Strategy on Energy Production and Consumption in China (2016-2030) proposes that the demand for clean energy (CE) and the proportion of non-fossil energy to generate electricity will be $50 \%$ by 2030. China has a clear strategic goal and direction to replace fossil energy with $\mathrm{CE}$ in the future. $\mathrm{CE}$ includes renewable energy and some non-renewable energy. Referring to energy that (1) can be replenished fully after consumption and (2) produces either no or very few pollutants, renewable energy comprises mainly wind, water, solar, biomass, and geothermal energy. Also classed as CE are some non-renewable energies that either minimize the production of pollutants or have been cleaned with specific technologies in the process of energy generation and consumption; these comprise mainly nuclear energy, natural gas, clean coal, and clean oil. In recent years, the clean 
energy renovation of existing buildings has been promoted effectively in China (MOHURD et al. 2015; MOHURD 2016, 2017; CABR 2017; Beijing Housing and Urban Rural Development Commission 2016). However, there is a lack of applicable standards for the renovation of existing urban residences (EURs), and CE transformation in EURs is yet to achieve standardization and become large in scale.

Currently, residential energy consumption accounts for a large proportion in all countries. In the United States (US), from 1950 to 2018, residential energy consumption has been ranked the third in the energy demand side. Consuming in 2018, the U.S. residential sector consuming almost equal amounts of natural gas $(43 \%)$ and electricity (42\%) (EIA). In German, the energy consumption of housing accounts for $25 \%$ of total energy consumption, and in France the energy consumption of the residential sector is 36870000 toe (metric tons of oil equivalent), ranking second among all industries (IEA). In China in 2016, building energy consumption accounted for $20.6 \%$ of the total energy consumption (China Building Energy Conservation Association 2018). To reduce the dependence on fossil energy, various countries and regions have promoted CE, with clean coal technology being an effective means of addressing coal-based pollution (Wang et al. 2020). In the process of urbanization in China, CE substitution in buildings is a new requirement of green development. The energy consumed in urban residential buildings in China comprises mainly (1) heating energy consumption in northern cities, (2) energy consumption in daily life of urban residents, and (3) energy consumption of air-conditioning in southern cities (Ding et al. 2017; Zhao et al. 2012). The energy consumption of residential air conditioning in China is far lower than that in the US, and detailed investigation of typical residential buildings in China and the US has shown that residents in China tend to use air conditioning when necessary, while residents turn on air conditioning all day in US. (Yi 2016). Therefore, the main existing alternative $\mathrm{CE}$ technologies in urban residential areas are (1) clean energy transformation of cooling and heating, (2) clean energy transformation of power system, (3) gas utilization technology.

Scholars have previously attempted to investigate energy consumption by using statistical methods and predictive models. In the $1970 \mathrm{~s}$, Ehrlich proposed the IPAT (impact $=$ population $\times$ affluence $\times$ technology) equation to express the quantitative relationship among economic growth, resources, and environment (Wang et al.2013). That equation was used widely in research of various fields (Vance et al. 2015; Ren et al. 2017), but the use of the formula still has some limitations because there are less independent variables in the formula. To overcome that deficiency, the STIRPAT model was built on the basis of the IPAT model (Cui and Liu 2013; Dietz and Rosa 1997).
Then, York et al (2003). revised the STIRPAT model.The STIRPAT model retains the relationship among driving forces in the IPAT model while taking population, economy, technology, and other driving forces as the main factors affecting the change of environmental pressure (Tahmassebi and Gandomi 2018). Meanwhile, ridge regression (RR) is a biased estimation regression method for collinear data analysis to deal with the collinearity of independent variables. RR has become the standard treatment method when the covariates are highly collinear (Zhao et al. 2020), and the literature contains many applications of RR to solve multi-collinearity in practical problems (Bedoui and Lazar 2020; Castiglione et al. 2020; Xu et al. 2020; Ali et al. 2020).

In summary, the demand for alternative $\mathrm{CE}$ technologies in EURs is a new requirement for the development of ecological civilization in China. In this paper, statistical methods are used to summarize the current situation of energy-saving transformation and CE application in EURs in China under different climatic divisions. The energy consumption of EURs is analyzed and predicted based on the STIRPAT model, and RR analysis of the functional relationship between the energy consumption of existing residential buildings and the influencing factors is carried out using the $\mathrm{R}$ software. An engineering application on Changdao Island in China's Shandong Province is addressed based on efficient alternative CE technology in EURs. The results provide basic data support for the planning and implementation of CE upgrade systems in urban residential areas in China, and the direction of $\mathrm{CE}$ utilization in low-carbon communities can be clarified and guided in the future.

The rest of this paper is organized as follows. Section 2 describes the survey and data analysis, Sect. 3 presents the results and model validation, and Sect. 4 presents the analysis of an engineering application involving a demonstration project on Changdao Island in China's Shandong Province. Finally, Sect. 5 presents conclusions and future directions.

\section{Methods}

\subsection{Survey and research process}

The types and quantities of CE are investigated in EURs in different climatic regions. The outdoor environment and relevant $\mathrm{CE}$ potential data are collected and analyzed, and important factors in the model for forecasting the strategy for efficient CE use are determined in EURs. The survey and research process are shown schematically in Fig. 1. 


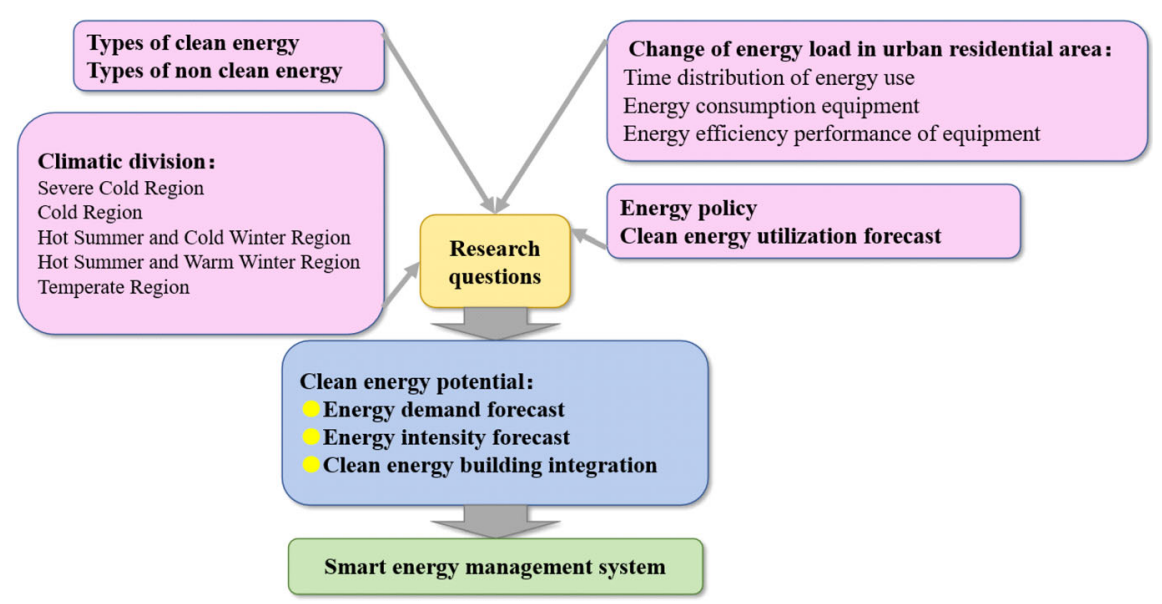

Fig. 1 Survey and research process

\subsection{Data analysis method}

\subsubsection{Architectural climatic division in China}

To account for local environmental conditions, building areas are divided according to climate. In the general design of civil buildings, the architectural climatic areas in China are divided into seven main regions. In this paper, as shown in Fig. 2, the CE distribution is divided into five climatic regions for simplicity.

\subsubsection{Predictive model}

The STIRPAT model establishes the factors that influence building energy consumption in EURs, and RR analysis is conducted on the model using the R software. The STIRPAT model is given by

$I=a P^{b} A^{c} T^{d} e$

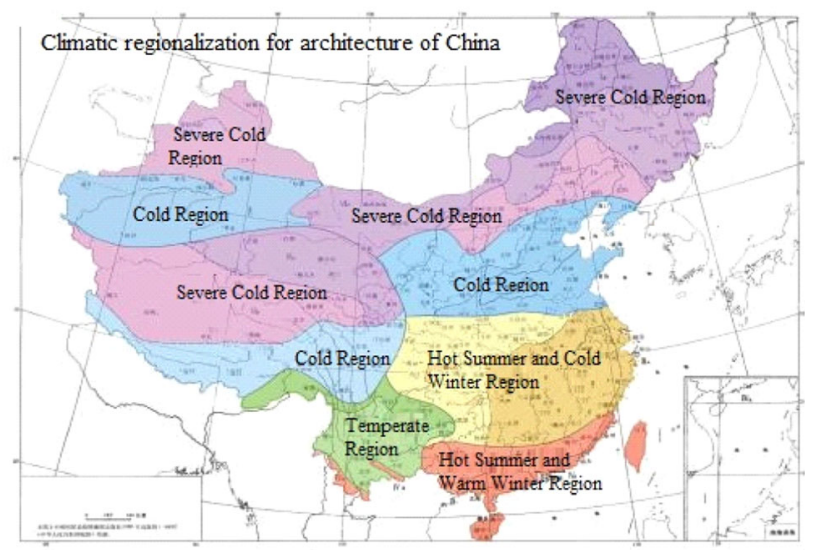

Fig. 2 Architectural climatic division in China
Because this is a nonlinear model, we use the logarithmic form of the formula

$\ln I=\ln a+b \ln P+c \ln A+d \ln T=\ln e$

where, $I$ is energy consumption, $P$ is population, $A$ is economic development level, $T$ is environmental load index under different technical conditions, $a$ is the model coefficient, $b, c$, and $d$ are the driving indexes of population, economy, and environmental load index under different technical conditions, respectively, and $e$ is the model error.

\section{Results}

\subsection{Energy-saving transformation in existing urban residences}

The total construction area of old residential areas (the old residential area refers to the residential area that was built before 2000, the backward public facilities affect the basic life of residents, and the residents have strong desire to transform) in China's 31 mainland provinces (the data of Hong Kong SAR, Macao SAR, Taiwan Province are absence) is 3.491 billion square meters, of which the amount in the cold and severe-cold regions was 1.512 billion square meters as of August 2015. After the large-scale application and promotion of clean energy technology in the cold and severe-cold regions, according to conservative calculation, 600,000 tons of standard coal can be saved and 1.5 million tons of $\mathrm{CO}_{2}$ emission can be reduced every year. The environmental benefits are significant. Meanwhile, doing so would improve the livability level of EURs significantly.

According to the 13th Five-Year Plan for renewable energy development (NDRC 2017b) issued by the National Development and Reform Commission of the People's Republic of China in December 2016, the total annual 
utilization of renewable energy was to be 730 million tce (metric tons of coal equivalent) by 2020 , including 580 million tce in utilization of commercial renewable energy. By the end of 2017, the installed capacity of electric power in China was 1.78 billion kilowatts, of which the installed capacity of renewable-energy power generation had reached around 650 million kilowatts, an increase from $33.1 \%$ in 2015 to $36.6 \%$ in 2017 . Wind power and solar photovoltaic power generation account for more than $10 \%$ of the power generation in Inner Mongolia, Gansu, Qinghai, and other provinces and have become important new sources of power.

As given in the Retrofitting of Existing Buildings Yearbook of 2018 (CABR 2018), the statistics for the energysaving renovation areas of EURs in China for 2017-2018 are shown in Fig. 3. To enhance the role of renewable energy in promoting the energy revolution, the national energy administration organizes all regions to prepare development plans for clean energy demonstration cities and clean energy application demonstration zones. According to statistics, the number of clean energy development and utilization demonstration projects in each province from 2017 to 2018 Fig. 4. In different cities, the advantages of energy resources are different. The types of renewable energy considered mainly for development includes solar photovoltaic and heat

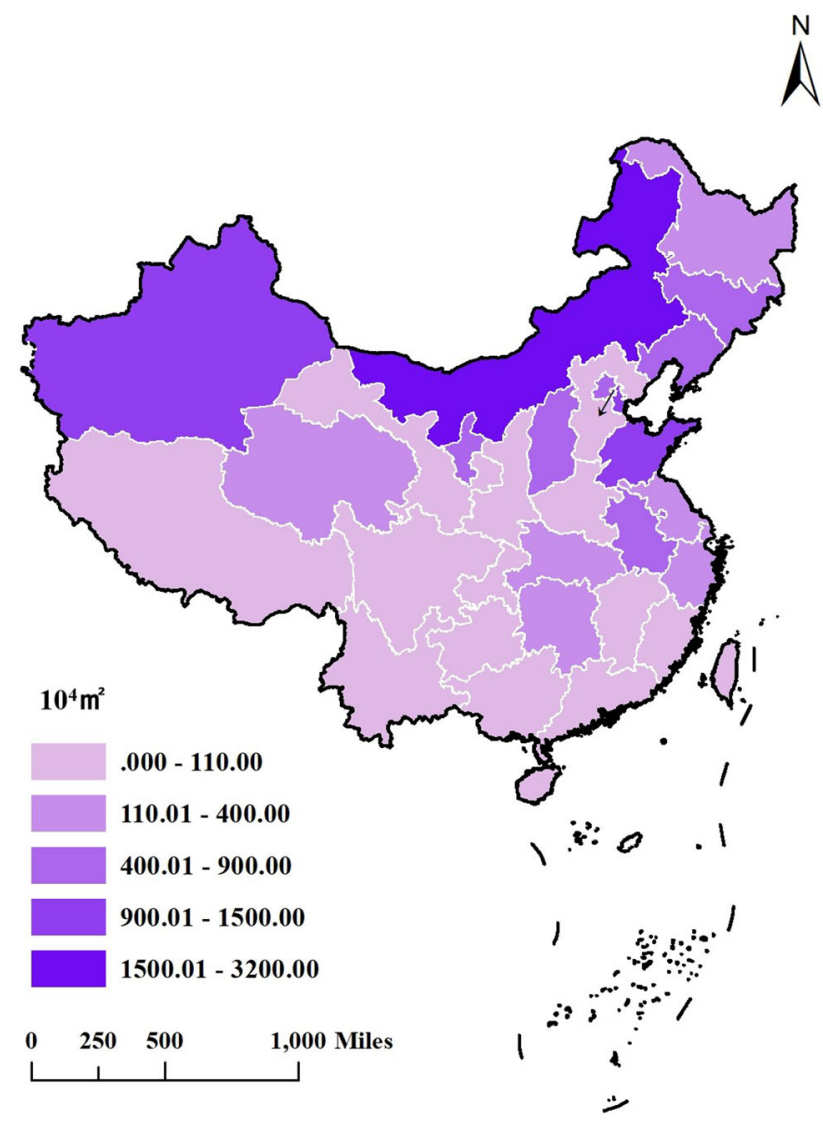

Fig. 3 Cumulative energy-saving reconstruction areas of existing urban residences (EURs) in China for 2017-2018

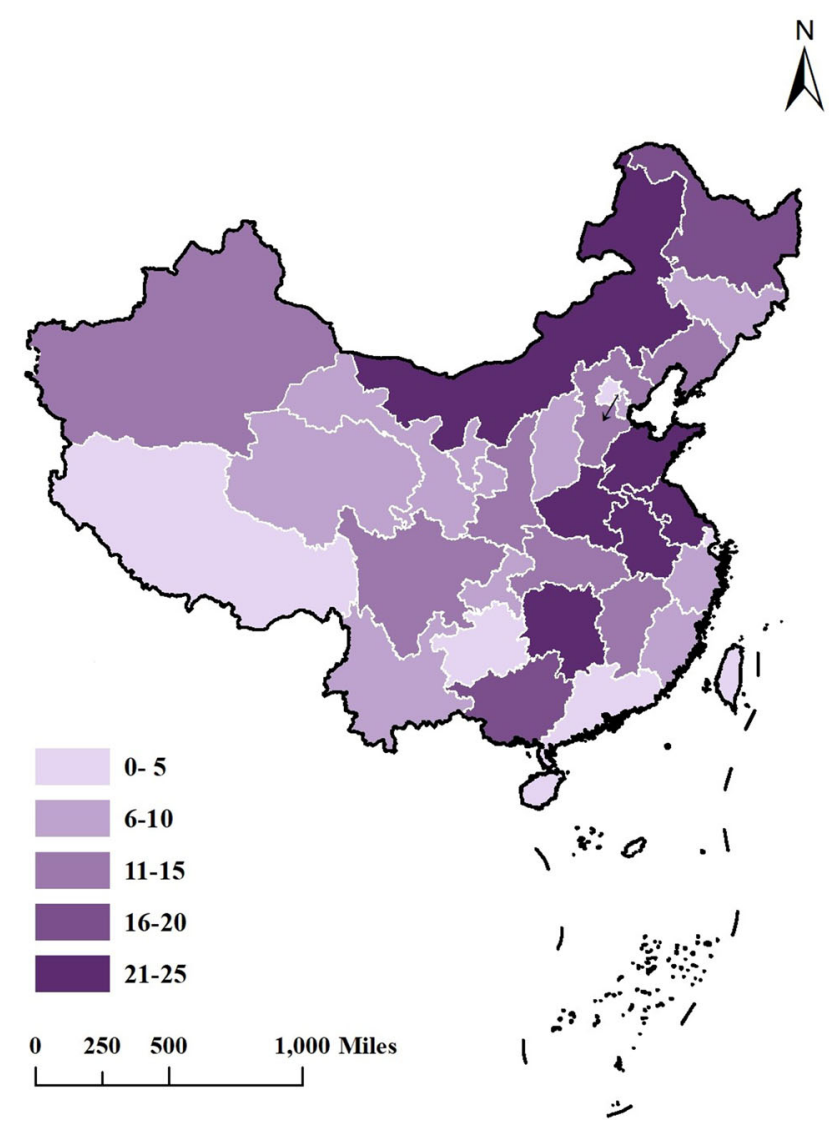

Fig. 4 Number of renewable-energy application demonstration projects in each province in 2018

utilization, shallow geothermal energy, biomass energy (waste power generation, etc.), wind power generation, air energy, marine energy, and hydropower, among others.

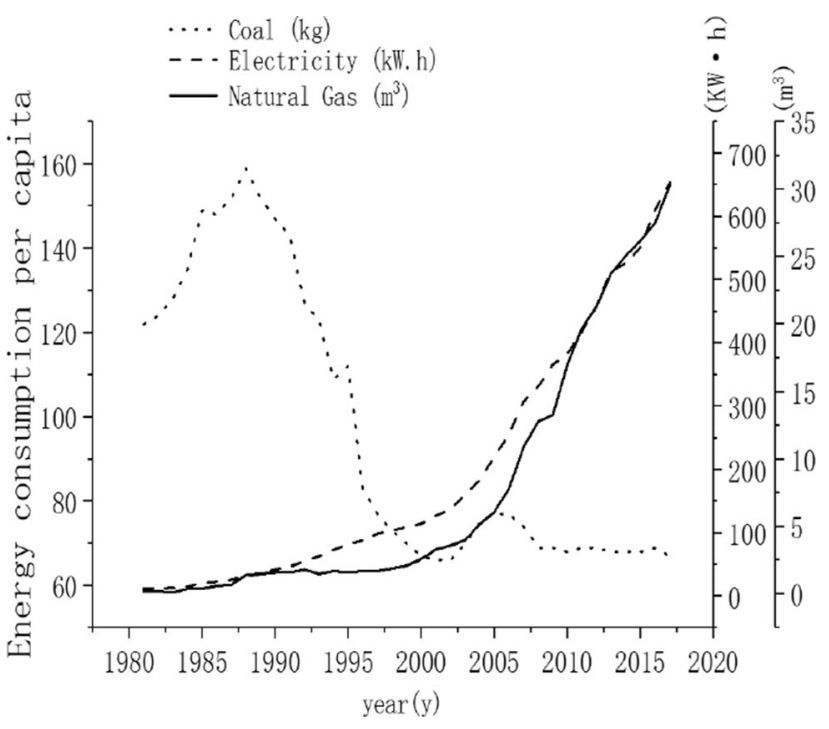

Fig. 5 Per capita use of different types of energy 


\subsection{Energy load in existing urban residences}

According to the statistical method used by the China Building Energy Conservation Association to calculate the energy consumption of EURs, the latter comprises mainly the electricity consumption of household appliances and the consumption of natural gas, which is related to the level of urban development, the level of energy technology, and the mode and concept of energy consumption of residents. The per capita energy consumption reflects the basic energy consumption of urban residents, which is related positively to the energy consumption of urban residential buildings.

As shown in Figs. 5 and 6, the per capita usage of electricity and natural gas is increasing, while that of coal is decreasing year by year; the per capita use of natural gas has increased by $142.4 \%$ since 2009 . The per capita energy consumption of the whole country and that of its cities are increasing; historically, the latter has always been higher than the former, but the gap has been decreasing, and in 2017 the per capita energy consumption of the whole country exceeded that of the cities. As can be seen, the energy-saving transformation of urban buildings and the utilization of CE technology have achieved initial results. Figure 7 shows that coal is the main source of fossil energy consumption in cold and severe-cold regions, while the consumption of electricity and natural gas is the highest in cold regions.

\subsection{Clean-energy power production by climatic division}

The CE data from the China Energy Statistical Yearbook 2018 (Department of energy statistics and National Bureau

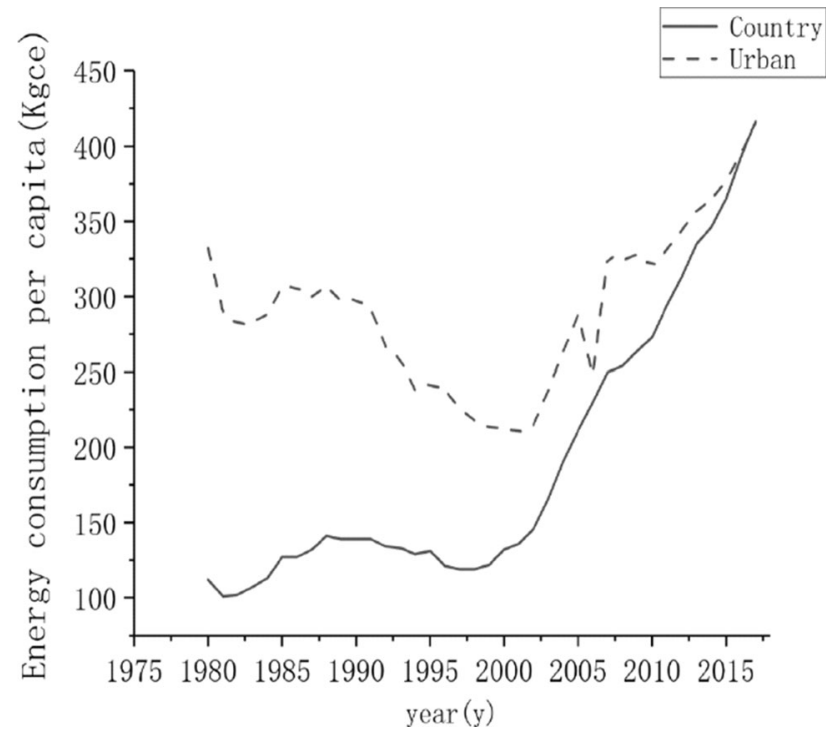

Fig. 6 Country and urban per capita energy use

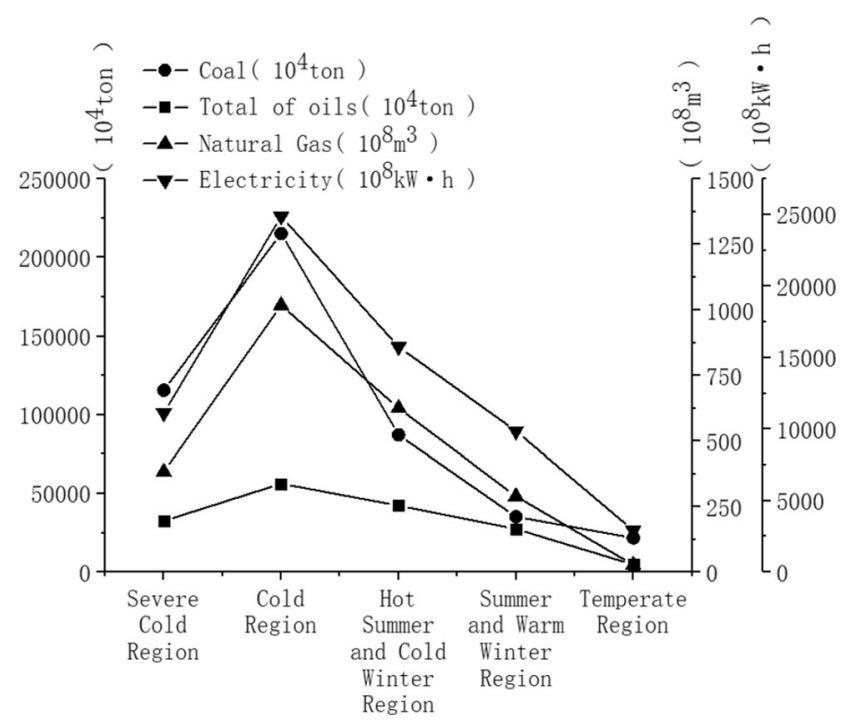

Fig. 7 Energy consumption by climatic region

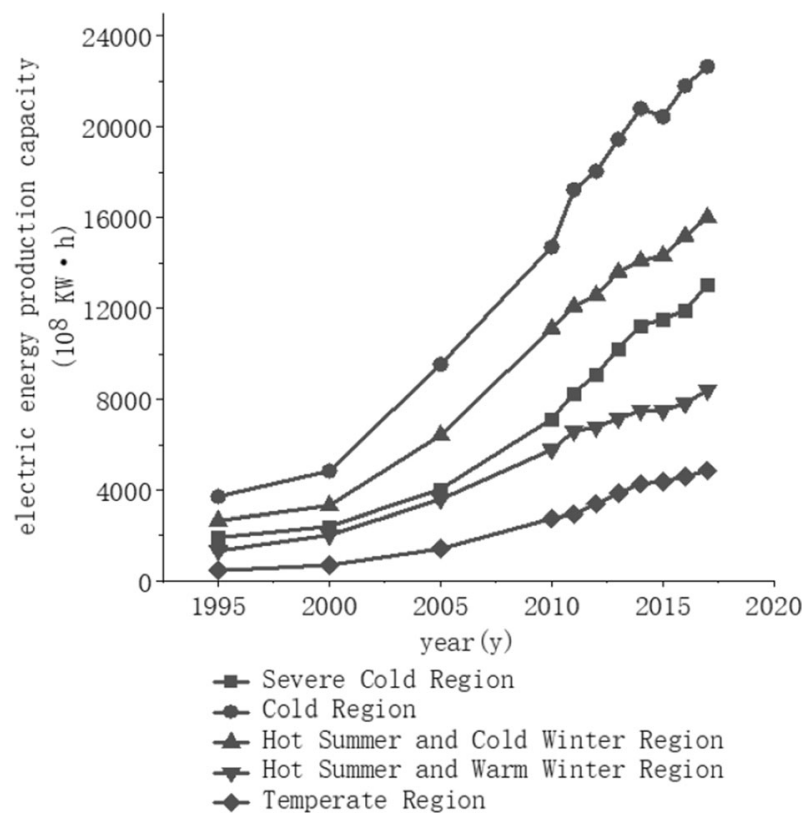

Fig. 8 Power generation by region

of Statistics 2018). Total power generation, nuclear power generation, wind power generation, solar photovoltaic power generation, and natural gas production are analyzed by Data maps and line charts, to explore the advantages of $\mathrm{CE}$ resources in various regions, providing support for the next step of alternative application of CE in EURs.

As shown in Figs. 8 and 9, the electricity generation in each region shows an upward trend. From high to low, the power generation is in the order of (1) the cold regions, (2) the hot summer and cold winter region, (3) the severe cold regions, (4) the hot summer and warm winter region, and (5) the temperate region. Power generation is highest in the 
$\stackrel{N}{N}$

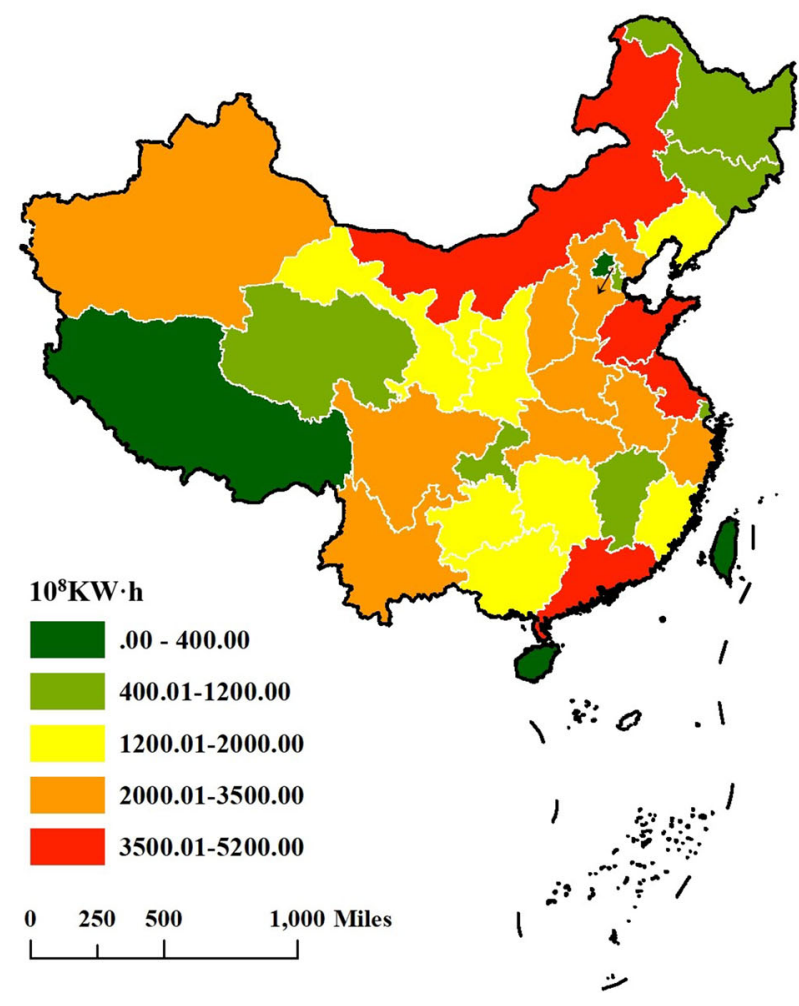

Fig. 9 Electric energy production capacity in 2017

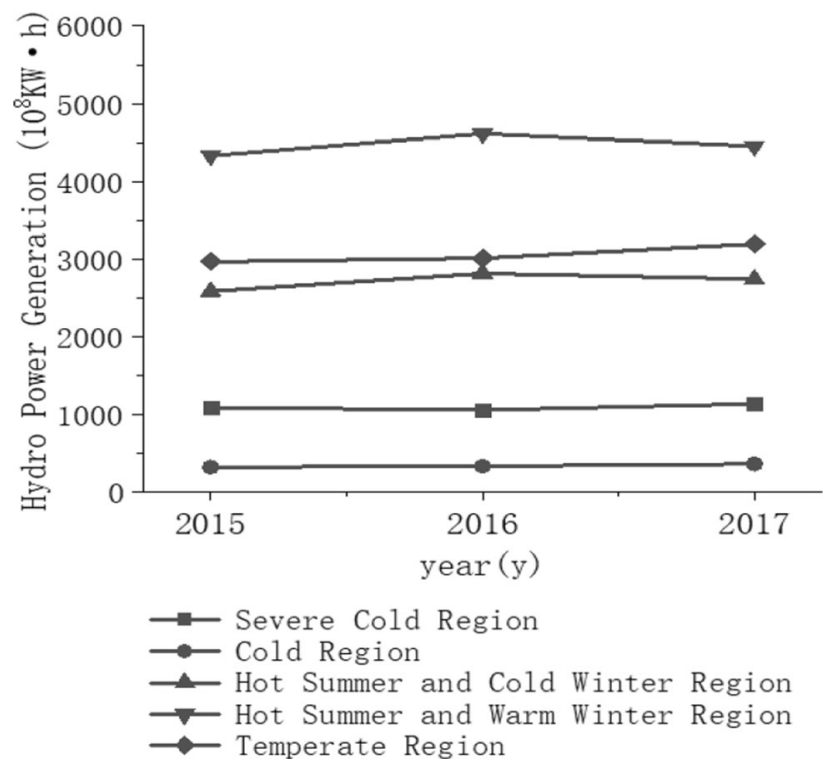

Fig. 10 Hydropower generation by region

cold regions, where the average electricity generation is 2.7 times than that in the temperate region.

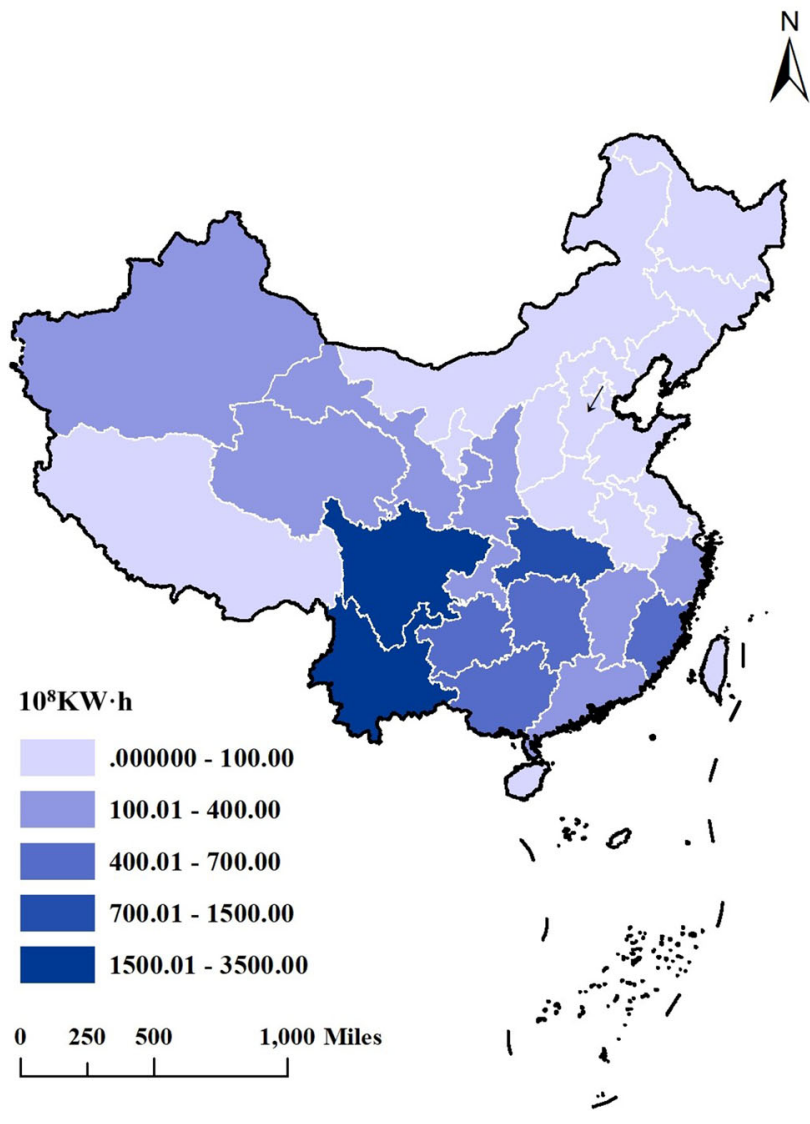

Fig. 11 Hydro power generation in 2017

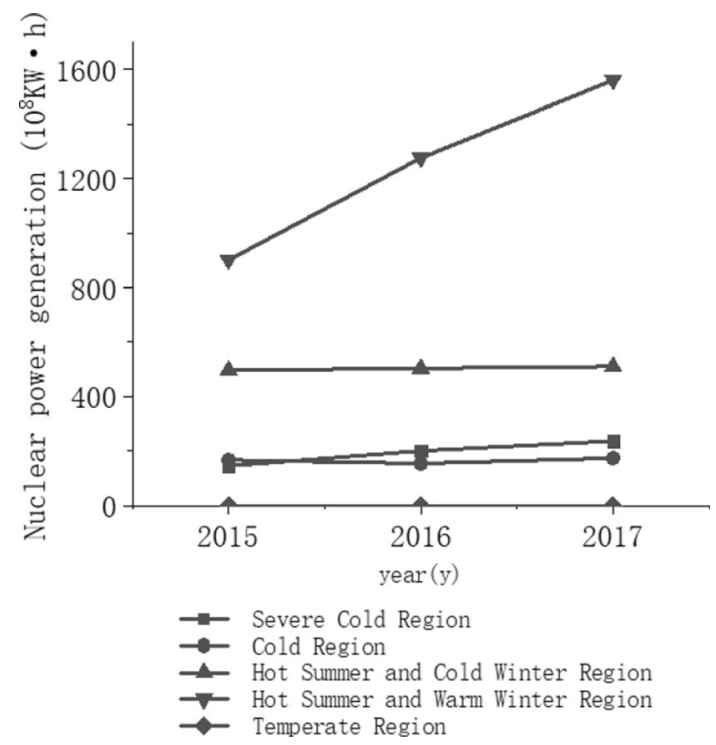

Fig. 12 Nuclear power generation by region

As shown in Figs. 10 and 11, the hydropower generation in various regions has tended to grow slowly and steadily in recent years. In the hot summer and warm winter region, the hot summer and cold winter region, and the temperate 


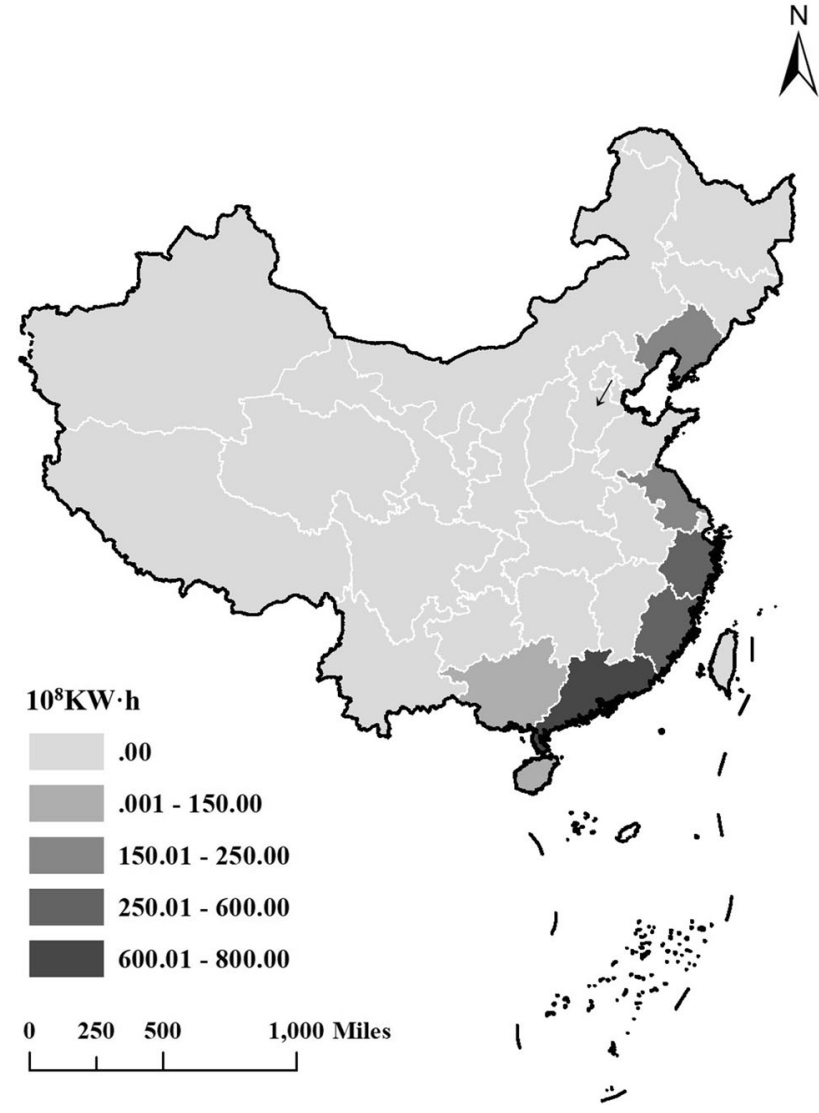

Fig. 13 Nuclear power generation in 2017

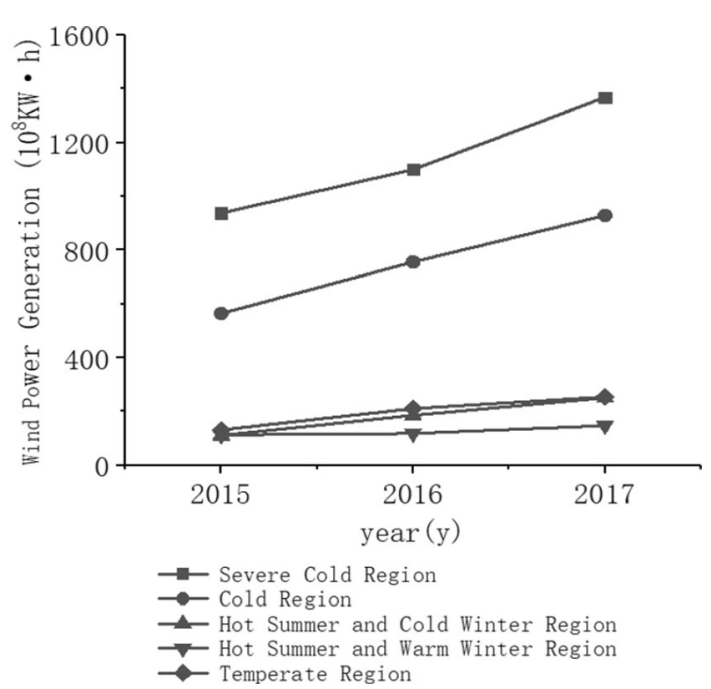

Fig. 14 Wind power generation by region

region, hydropower generation is more developed than in the other regions. Yunnan and Sichuan provinces have the best hydropower development because of their geographical advantage, being located in the upper reaches of the Yangtze River Basin with a huge terrain drop.

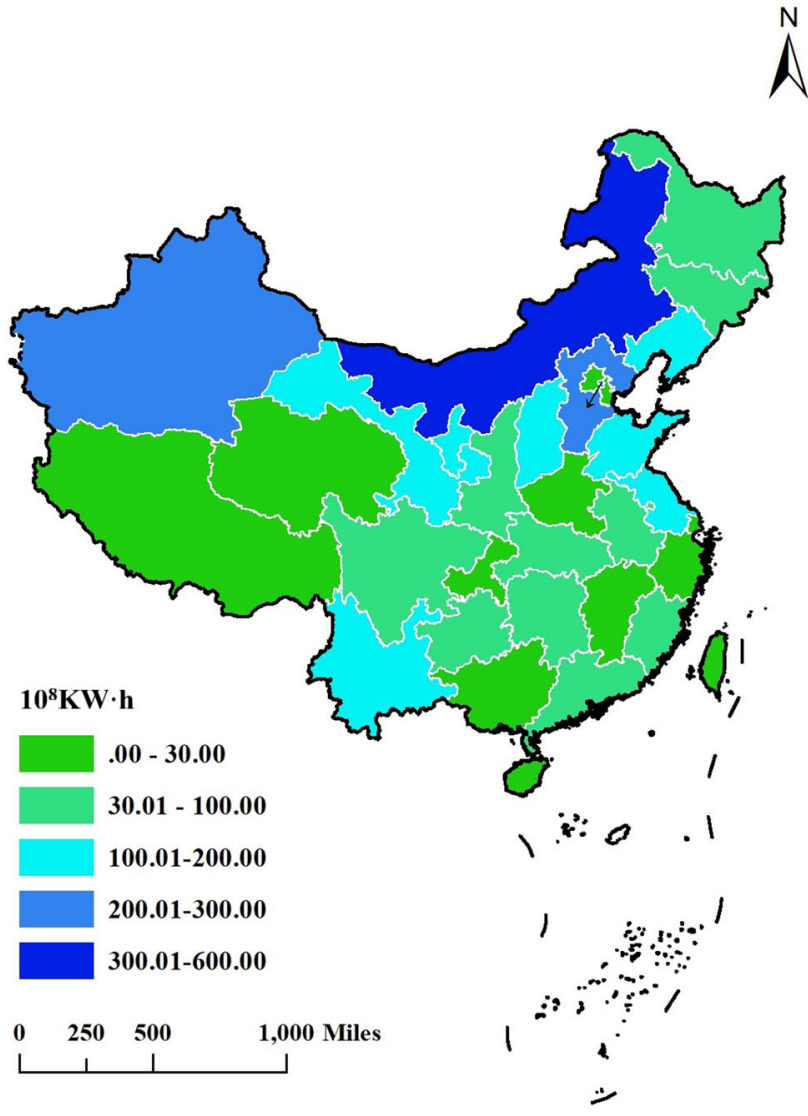

Fig. 15 Wind power generation of 2017

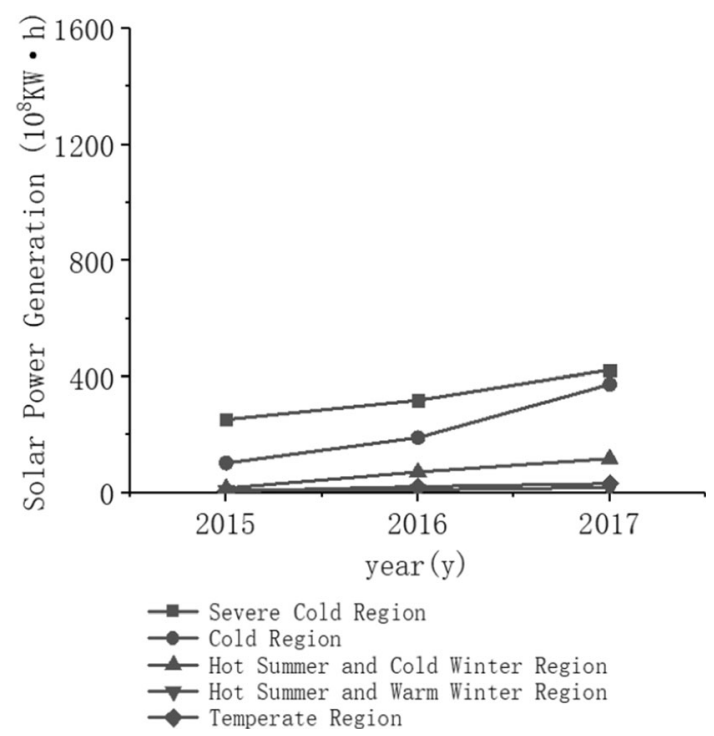

Fig. 16 Solar photovoltaic power generation

As shown in Figs. 12 and 13, nuclear power generation is concentrated mainly in the coastal provinces, including Liaoning, Jiangsu, Zhejiang, Fujian, Guangdong, Guangxi, 


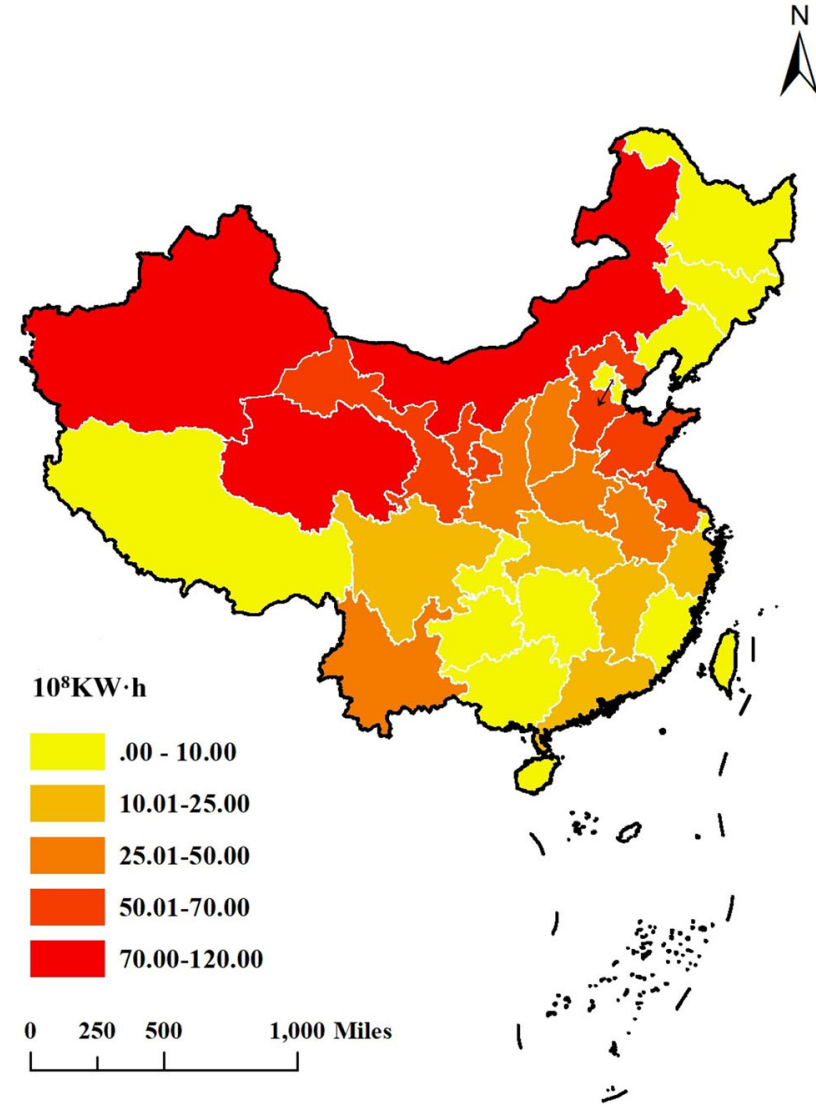

Fig. 17 Solar photovoltaic power generation in 2017

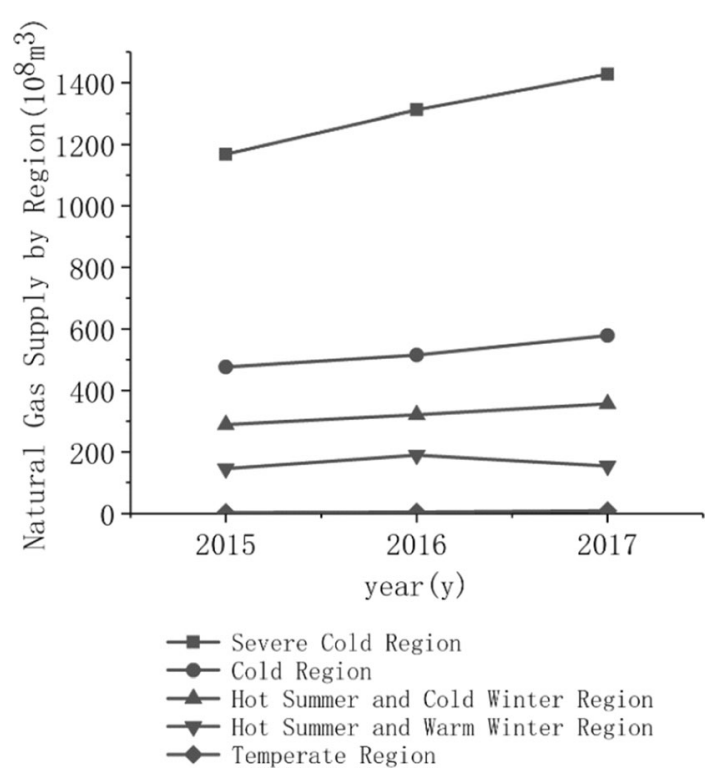

Fig. 18 Supply of natural gas by region

and Hainan. From the perspective of climatic division, nuclear power generation is the most abundant in the hot summer and warm winter region, having increased by $73.3 \%$ from 2015 to 2017.

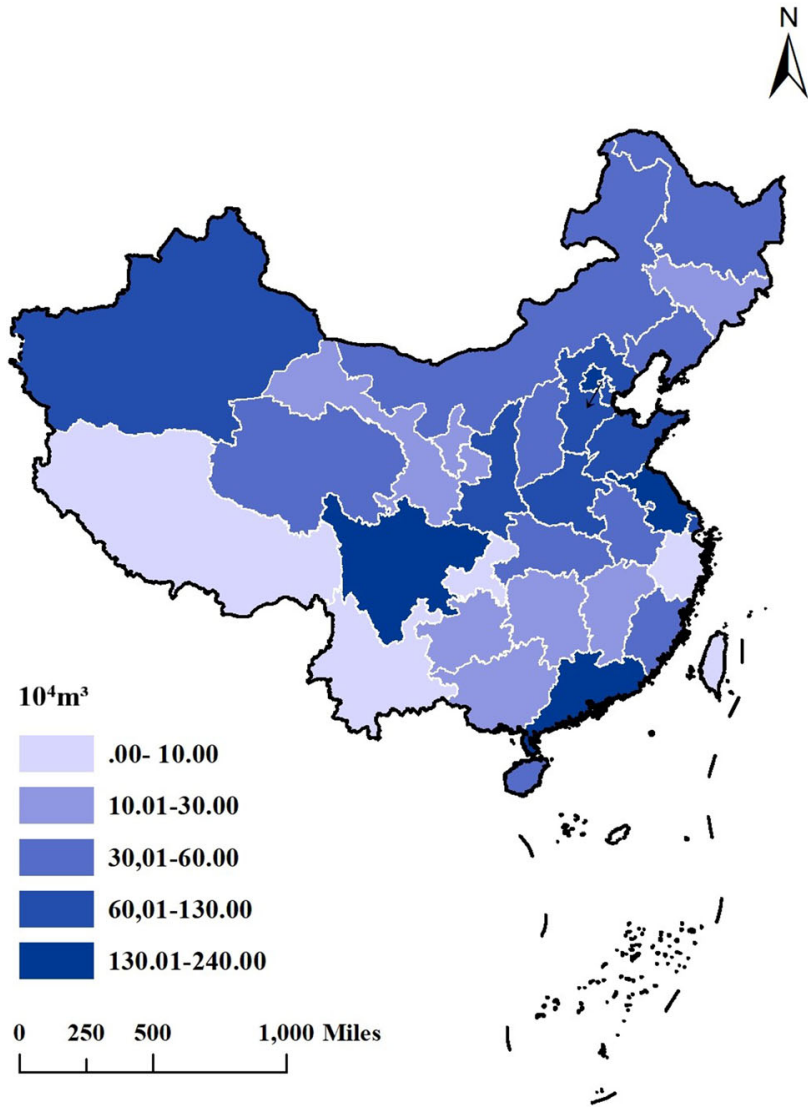

Fig. 19 Supply of natural gas

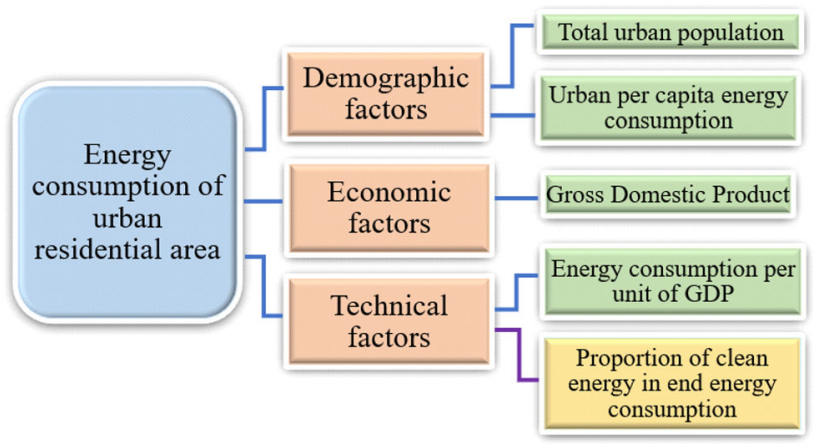

Fig. 20 Model of energy consumption in urban buildings

As shown in Figs. 14 and 15, wind power generation is concentrated mainly in Inner Mongolia, Xinjiang, Gansu, Ningxia, Hebei, Liaoning, Yunnan, and other regions. From the perspective of climatic division, wind power generation is the most abundant in the severe cold regions, having increased by $45.8 \%$ from 2015 to 2017 .

As shown in Figs. 16 and 17, Inner Mongolia, Xinjiang, Gansu, Ningxia, and Qinghai are major provinces of solar photovoltaic power generation. From the perspective of climatic division, solar photovoltaic energy resources are 
Table 1 Data for model

\begin{tabular}{lllllll}
\hline Year & $\begin{array}{l}\text { Energy consumption of } \\
\text { urban residential area } \\
\left(10^{4} \text { tce }\right)\end{array}$ & $\begin{array}{l}\text { Total urban } \\
\text { population } \\
\left(10^{4}\right)\end{array}$ & $\begin{array}{l}\text { Gross } \\
\text { domestic } \\
\text { product }\left(10^{8}\right. \\
\text { Yuan })\end{array}$ & $\begin{array}{l}\text { Energy consumption per } \\
\text { unit of GDP }\left(10^{4} \text { Yuan/ }\right.\end{array}$ & $\begin{array}{l}\text { Urban per capita } \\
\text { energy consumption } \\
\left(10^{4} \text { tce }\right)\end{array}$ & $\begin{array}{l}\text { Proportion of clean energy } \\
\text { in terminal energy } \\
\text { consumption }(\%)\end{array}$ \\
\hline 2009 & 23,600 & 64,512 & 349,081 & 1.16 & 328 & 7.9 \\
2010 & 24,300 & 66,978 & 413,030 & 0.88 & 320 & 9.0 \\
2011 & 25,300 & 69,079 & 489,301 & 0.86 & 331 & 9.0 \\
2012 & 26,800 & 71,182 & 540,367 & 0.83 & 344 & 9.9 \\
2013 & 28,800 & 73,111 & 595,244 & 0.79 & 357 & 10.7 \\
2014 & 30,100 & 74,916 & 643,974 & 0.76 & 364 & 11.7 \\
2015 & 32,000 & 77,116 & 689,052 & 0.63 & 377 & 395 \\
2016 & 33,900 & 79,298 & 743,586 & 0.60 & 395 & 13.4 \\
\hline
\end{tabular}

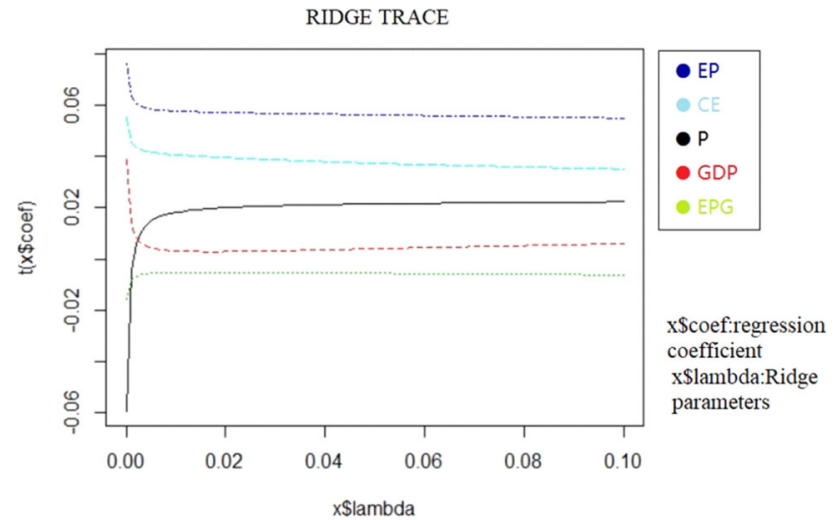

Fig. 21 Ridge trace (EP refers to urban per capita energy consumption, CE refers to proportion of clean energy in terminal energy consumption, $\mathrm{P}$ refers to total urban population, GDP refers to gross domestic product, EPG refers to energy consumption per unit of GDP)

abundant in the cold and severe cold regions, and the solar photovoltaic power generation capacity in the cold regions increased significantly in 2017, with an increase of $261.9 \%$ compared with 2015.

In summary, the following can be seen. (1) The nuclear power generation capacity in the hot summer and warm winter region is ahead of that in the other regions, and the power generation capacity is increasing notably. (2) Wind power generation and solar photovoltaic power generation capacity are strong in the cold and severe cold regions, and the power generation capacity is also increasing year by year. (3) The CE power generation in each region accounts for a small proportion of the total power generation. (4) The CE power generation in each region is related positively to the total power generation.

As shown in Figs. 18 and 19, the areas of natural gas supply that exceeded $150 \times 10^{8} \mathrm{~m}^{3}$ in 2017 were Sichuan,
Guangdong, Jiangsu, and Beijing. The multi-energy complementary mode is encouraged in Sichuan Province, for example, natural gas price has been reduced to 2.2-2.3 Yuan $/ \mathrm{m}^{3}$ to increase the utilization of natural gas by residents The natural gas supply in each region shows an upward trend and ranks from high to low as (1) the severe cold regions, (2) the cold regions, (3) the hot summer and cold winter region, (4) the hot summer and warm winter region, and (5) the temperate region. Therefore, sufficient natural gas supply is the advantage of clean energy alternatives in cold regions.

\subsection{Regression analysis of urban residential energy consumption}

The main factors that influence urban residential energy consumption are total population, per capita energy consumption, gross domestic product (GDP), and energy consumption per unit of GDP. In this paper, the proportion of $\mathrm{CE}$ in the terminal energy consumption is added. According to the STIRPAT model in Sect. 2.2.2, the energy-consumption model of urban buildings is established as shown in Fig. 20. Regression analysis is carried out with data from 2009 to 2016, specific those obtained from the 2018 China Energy Statistical Yearbook (Department of energy statistics and National Bureau of Statistics 2018), the 2018 Statistical Yearbook of Urban and Rural Construction in China (Mohurd 2019), and the 2012-2018 Annual Research Report on China's Building Energy Consumption (CABEE 2012-2018), as given in Table 1.

First, multiple linear regression is performed on the data, and the multi-collinearity of the data is obtained by the Klein discriminant method. Therefore, multiple linear regression cannot be used, and instead RR is used as mentioned above. $R R$ is a biased estimation regression method that is used especially in the analysis of collinear 

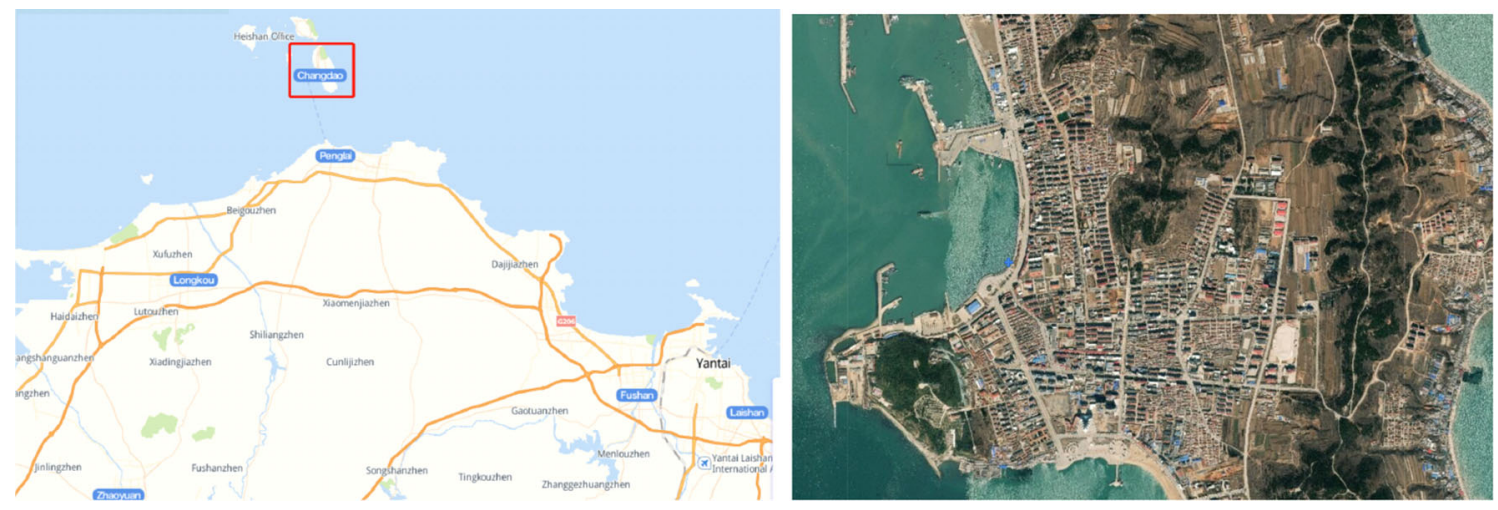

Fig. 22 Engineering application in Changdao, Shandong Province

data. After $\mathrm{R}$ software calculation, the ridge trace is as shown in Fig. 21. According to the selection principle of $K$ value (lambda value), this paper takes the $K$ value (lambda value) recommended by the $\mathrm{R}$ software, i.e., $K=0.01215678$. The regression equation is as follows:

$$
\begin{aligned}
\ln y= & 0.023898 \mathrm{In} P=0.00630 \mathrm{InGDP} \\
& -0.006651 \mathrm{InEPG}+0.058895 \mathrm{InEP} \\
& +0.037602 \mathrm{InCE}+10.235879
\end{aligned}
$$

where, EPG is the energy consumption per unit of GDP, EP is the urban per capita energy consumption, and CE is the proportion of CE in the terminal energy consumption.

The results show that the coefficient of determination $R^{2}$ (multiple $R$-squared) is $0.9984(0.9950)$, therefore the model established in Eq. (3) has high goodness of fit. The results from large to small in order of influence are (1) per capita energy consumption, (2) proportion of CE in terminal energy consumption, (3) total population, (4) energy consumption per unit of GDP, and (5) total population. The fitting results show that $\mathrm{CE}$ accounts for a large and significant proportion in the influencing factors of EURs, which means that the utilization of CE technology will be a very important direction for the transformation of EURs. The results of ridge regression shows that the energy consumption of urban residential buildings increases year by year with the increase of GDP and energy consumption per capita. Compared with 2009, the energy consumption of urban residential buildings increased by $43.6 \%$ in 2016. Natural gas also increased from $7.9 \%$ to $13.4 \%$, but this still cannot meet the demand of energy consumption in urban residences.

\section{Engineering application}

The climate characteristics, energy resources, building types, use rules, and control performance of EURs will be further discussed. According to the principles of energy conservation and local conditions, the specific CE alternatives for EURs in typical cities will be determined reasonably to meet the goals of the Energy and Production and Consumption Revolution Strategy (2016-2030). At the same time, the CE utilization rate in the future transformation should be predicted reasonably.

As shown in Fig. 22, this demonstration project is on Changdao Island in Shandong Province, which is one of the cold regions, is the first large-scale clean energy transformation project. The Changdao project involves 17 residential communities and an urban area of 2.45 million square meters. The demonstration area is approximately $4 \mathrm{~km}^{2}$. According to Figs. 11, 13, and 15, Shandong Province's main renewable-energy resources are solar photovoltaic energy, geothermal energy, marine energy, and biomass energy. Therefore, an efficient CE utilization strategy for the EURs in Changdao is formulated, and renewable energy is used fully as the heating source, i.e., a renewable low-grade heat source combining an air-source energy tower and a sea-water-source heat pump is used to realize the high-efficiency utilization of CE.

In addition to clean heating, Changdao has electricity demands for household appliances, cooking, and elevators, among others. It is recommended to comprehensively utilize clean power generation technologies such as solar photovoltaic power generation, wind power generation, and nuclear power generation to transform energy supply system and the power system of the district.

\section{Discussion}

In this paper, the geographical distribution of $\mathrm{CE}$ power generation in primary energy production in China has been discussed in depth. The proportion of $\mathrm{CE}$ in end-use consumption is increasing to meet the aim of peak $\mathrm{CO}_{2}$ emissions before 2030, and the proportion of CE consumption reflects the level of national energy technology. 
A statistical analysis of CE utilization in EURs has been completed. A model for predicting CE demand has been established, and the CE contribution rate in the urban energy consumption has been analyzed based on the RR method. The potential of clean energy to replace traditional energy has been analyzed based on the climatic division.

However, CE usage in EUR project applications is not yet sufficiently popular. The demand for CE will be measured and investigated in 2020 by the project team. Based on the dynamic load characteristics of typical EUR areas and combined with energy-saving and environmental indicators, a CE replacement technology that is applicable and efficient in EURs will be proposed by the project team, and a strategy for the efficient use of CE in EURs will be combined with $\mathrm{CO}_{2}$ emission target.

Author contributions Conceptualization, LZ; methodology, WC; investigation, QL; writing-original draft preparation, WC; writing-review and editing, QL; visualization, LZ. All authors have read and agreed to the published version of the manuscript.

Funding This research was funded by the National Key Research and Development Plan (2018YFC0704800).

\section{Declaration}

Conflicts of Interest The authors declare no conflict of interest. The funders had no role in (1) the design of the study, (2) the collection, analyses, or interpretation of the data, (3) the writing of the manuscript, or (4) the decision to publish the results.

Open Access This article is licensed under a Creative Commons Attribution 4.0 International License, which permits use, sharing, adaptation, distribution and reproduction in any medium or format, as long as you give appropriate credit to the original author(s) and the source, provide a link to the Creative Commons licence, and indicate if changes were made. The images or other third party material in this article are included in the article's Creative Commons licence, unless indicated otherwise in a credit line to the material. If material is not included in the article's Creative Commons licence and your intended use is not permitted by statutory regulation or exceeds the permitted use, you will need to obtain permission directly from the copyright holder. To view a copy of this licence, visit http://creativecommons. org/licenses/by/4.0/.

\section{References}

Ali M, Prasad R, Xiang Y, Yaseen ZM (2020) Complete ensemble empirical mode decomposition hybridized with random forest and kernel ridge regression. J Hydrol 584:124647. https://doi. org/10.1016/j.jhydrol.2020.124647 (ISSN 0022-1694)

Bedoui A, Lazar NA (2020) Bayesian empirical likelihood for ridge and lasso regressions. Comput Stat Data Anal 145:106917. https://doi.org/10.1016/j.csda.2020.106917 (ISSN 0167-9473)

Beijing Housing and Urban Rural Development Commission (2016) Technical specification for energy efficient renovation of existing residential buildings. Beijing Housing and Urban Rural Development Commission, Beijing

CABEE (2012-2018) 2012-2018 Annual Research Report on China's Building Energy Consumption. CABEE, Beijing

CABR (2017) Technical specification for green retrofitting of existing building. CABR, Beijing

CABR (2018) Retrofitting of existing buildings yearbook of 2018. CABR, Beijing

Castiglione S, Serio C, Mondanaro A, Melchionna M, Carotenuto F, Di Febbraro M, Profico A, Tamagnini D, Raia P (2020) Ancestral state estimation with phylogenetic ridge regression. Evol Biol 47(3):220-232

China Building Energy Conservation Association (2018) China building energy consumption research report 2018.

Cui Z, Liu X (2013) Urban building energy consumption forecast based on the IPAT theory. Adv Mater Res 689:482-486

Dietz T, Rosa EA (1997) Effects of population and affluence on $\mathrm{CO}_{2}$ emissions. Proc Nat Ac Sci 94(10):175-179

Ding Q, Cai W, Wang C, Sanwal M (2017) The relationships between household consumption activities and energy consumption in china-an input-output analysis from the lifestyle perspective. Appl Energy 207:520-532

Dutta R (2020) Use of clean, renewable and alternative energies in mitigation of greenhouse gases. Encycl Renew Sustain Mater 3:821-834. https://doi.org/10.1016/B978-0-12-803581-8.11048-3

EIA: https://www.eia.gov/

IEA: https://www.iea.org/

MOHURD and AQSIQ (2015) Assessment standard for green retrofitting of existing building. MOHURD, Beijing

MOHURD (2016) Technical code for the retrofitting of existing residential building on using function. MOHURD, Beijing

MOHURD (2017) Technical standard for green retrofitting of existing community. MOHURD, Beijing

MOHURD (2019) Statistical yearbook of urban and rural construction in China 2018. MOHURD, Beijing

NDRC (2017a) National Energy Administration. Revolutionary strategy of energy production and consumption (2016-2030). NDRC, Beijing

NDRC (2017b) 13th Five-Year Plan for Renewable Energy Development. NDRC, Beijing

Ren H, Chen Y, Cai W, Wang X, Deng Y (2017) Analysis on influencing factors of energy consumption of urban architecture in Chongqing based on STIRPAT model. Heat Vent Air Cond 47(11):40-44

Tahmassebi A, Gandomi AH (2018) Building energy consumption forecast using multi-objective genetic programming. Measurement 118:164-171

Vance L, Eason T, Cabezas H (2015) Energy sustainability: consumption, efficiency, and environmental impact. Clean Technol Environ Policy 17(7):1-12

Wang L, Lu Z (2013) Lu Q (2013) Survey on energy consumption of public buildings in China. Ener Environ 01:15-17

Wang X, Tang Y, Wang S, Schobert HH (2020) Clean coal geology in China: research advance and its future. Int J Coal Sci Technol 7:299-310

Xu W, Liu X, Leng F, Li W (2020) Blood-based multi-tissue gene expression inference with Bayesian ridge regression. Bioinformatics 36(12):3788-3794

Yi J (2016) Thinking about the concept of building energy conservation in China. China Construction Industry Press, Beijing

York R, Rosa EA, Dietz T (2003) STIRPAT, IPAT and Impact: analytic tools for unpacking the driving forces of environmental impacts. Ecol Econ 46:351-365

Zhao X, Li N, Ma C (2012) Residential energy consumption in urban China: a decomposition analysis. Energy Policy 41:644-653

Zhao S, Liao J, Yu D (2020) Model averaging estimator in ridge regression and its largesample properties. Stat Pap 61:1719-1739 